\title{
Dizziness and nausea vomitting induced by ropinirole therapy in an elderly patient with Parkinson's disease : a case report
}

\author{
Emilia Sidharta*1, Hanny Cahyadi ${ }^{1,2}$ \\ ${ }^{1}$ Department of Pharmacy National Hospital, Surabaya, East Java, Indonesia \\ ${ }^{2}$ Faculty of Pharmacy, University of Surabaya, East Java, Indonesia \\ *Corresponding author: sidhartaemilia@gmail.com
}

\begin{abstract}
Background: Ropinirole is a non-ergoline dopamine agonist drug that is widely used in a therapy for patients diagnosed with Parkinson's disease. In long-term use, several published studies have mentioned the occurrence of side effects of ropinirole in the therapy of Parkinson's disease, but there has been no case report on the occurrence of side effects in the form of dizziness and nausea-vomiting, especially in Indonesia.

Case Presentation: This case study reported the occurrence of side effects in the form of dizziness and nausea-vomiting experienced by a 74-year-old elderly who was undergoing a treatment in a hospital in Indonesia. The patient was diagnosed with Parkinson's 8 months ago and has been given a combination therapy of levodopa-benserazide and trihexyphenidyl. During such period, no side effects occurred. The therapy was then supplemented with $2 \mathrm{mg}$ ropinirole because the patient complained that his hand started shaking again. Some side effects arose after the addition of $2 \mathrm{mg}$ ropinirole; therefore, the side effects were thought to be associated with ropinirole. The assessment methods used were the time-series data collection followed by causality analysis using the Naranjo Scale. The analysis showed a score of 6, indicating Probable. Based on the literature review, side effects such as nausea and vomiting may occur due to the activation of dopamine D2 receptors in the Chemoreceptor Trigger Zone (CTZ) area. The CTZ area consists of several receptors, which are sensitive to the causative agent of emesis and produce information on the vomiting center that has a role in triggering the vomiting reflexes.

Conclusion: Analysis using Naranjo Scale shows a score of 6 which indicates a probable association between dizziness, nausea-vomiting and ropinirole in an elderly patient with Parkinson's Disease.

Keywords: ropinirole, Parkinson, case report, elderly, side-effects
\end{abstract}

\section{Introduction}

Ropinirole is a non-ergoline dopamine-agonist that is widely used as a therapy for patients with Parkinson's disease. As a therapy at the early stage of Parkinson, ropinirole can be used as a single therapy or combined with levodopa (Pahwa et al., 2004). Long-term use of ropinirole possibly causes several side effects. Some common side effects of ropinirole can be known through tertiary information sources and drug leaflets. Based on the information on the product leaflet, some side effects are commonly found, including nausea and vomiting. Apart from the information in the product leaflet, several published studies have reported some side effects caused by ropinirole, for example, Othello Syndrome (Pal et al., 2012) and psychosis (Grover \& Ghosh, 2010). Although some literature has mentioned the side effects that can be caused by the long-term use of ropinirole, the number of case reports and published studies about this topic remains limited, especially in Indonesia. 


\section{Methods}

We reported a case of ropinirole side effects and described the pharmacological background of these side effects. The assessment methods used were time-series data collection followed by causality analysis using the Naranjo Adverse Drug Probability Scale.

\section{Case Report}

Mr. BK, a 74-year-old man, had been diagnosed with Parkinson's Disease since October 2018. At that time, he went to the doctor because he had had troublesome symptoms such as tremor and walking disorders for six months. After the doctor did some examination, he was diagnosed with Parkinson's Disease and given a therapy of $2 \mathrm{mg}$ trihexyphenidyl and a combination of $100 \mathrm{mg}$ levodopa and $25 \mathrm{mg}$ benserazide. Both medications were taken 3 times a day. The treatment gave him improved conditions, evidenced by the doctor's assessment 2 months after that. Throughout the treatment, the patient also used a number of heart medications, such as $5 \mathrm{mg}$ isosorbide dinitrate which was taken twice a day every morning and night, and $300 \mathrm{mg}$ irbesartan taken every morning. The patient said that he had used the drug for several years without experiencing significant problems.

However, 6 months later (around June 2019), the patient came back to the doctor and complained that his right hand was shaking again. Therefore, the doctor added $2 \mathrm{mg}$ ropinirole which was advised to be taken once a day at night. Two weeks after using $2 \mathrm{mg}$ of ropinirole therapy, the patient came back to the hospital and told the pharmacist that he had dizziness also nausea and vomiting after using the additional medicine.

To overcome those symptoms, he stopped using ropinirole for several days and the symptoms did not occur anymore. After the symptoms disappeared, the patient continued using the medication and the symptoms reappeared. Finally, the patient divided ropinirole tablet into 2 pieces and only drank half of it at night without any consultations with the doctor. The effects of dizziness and nausea-vomiting had been reduced but still felt by the patient after taking only half of the tablet of ropinirole. The pharmacist conducted an assessment of the patient's complaints and analyzed the possibility of drug side effects.

After investigating the side effects of the drug using the Naranjo Adverse Drug Probability Scale, a score of 6 was obtained, which indicated Probable. Therefore, in July 2019, the doctor decided to stop the treatment involving $2 \mathrm{mg}$ ropinirole because it was suspected that the patient suffered from the side effects caused by the use of Ropinirole.

\section{Discussion}

Since being approved as an initial therapy and adjunctive therapy for Parkinson's by the United States' Food and Drug Administration (FDA) in 1997 and Badan Pengawas Obat dan 
Makanan (BPOM) in 2012, ropinirole has been widely used as a treatment for Parkinson's. Ropinirole is a non-ergoline dopamine agonist with a preferential affinity for D2-like receptors (D2, 3, 4). It has the highest affinity with D3 receptors which are concentrated in the limbic areas of the brain and may account for some of the neuropsychiatric effects. Lesser, but still significant, affinity is seen at D2 receptor in the striatum, accounting for the prominent benefits on the motor symptoms of Parkinson's Disease (Shill \& Stacy, 2009).

Several published journals and drug leaflets have mentioned that one of the common side effects that often occur in the long-term use of ropinirole are nausea and vomiting (Pahwa et al., 2004). A systematic review conducted in the United States stated that the use of ropinirole is associated with high nausea (HR 5,924 [4,410-7,959], p < 0.001) and vomiting (HR 4,628 [3,035-7,057], $p<0,0001)$. The publication also mentioned that of all the side effects that have been reported, nausea and vomiting were experienced by more than $50 \%$ of patients (Kurin et al., 2018).

In the case of this 74-year-old man, the effects of dizziness and nausea and vomiting were felt after using $2 \mathrm{mg}$ ropinirole for about 2 weeks. Analysis of the occurrence of side effects of the drug was carried out by the pharmacist using the Naranjo Adverse Drug Probability Scale. This showed a score of 6, indicating Probable (Table 1 and 2). Based on the literature review, these side effects can occur due to the stimulation of dopamine D2 receptors in the Chemoreceptor Trigger Zone (CTZ) area.

Table 1. Naranjo adverse drug reaction probability scale

\begin{tabular}{|c|c|c|c|c|c|}
\hline No. & Question & Yes & No & $\begin{array}{l}\text { Don't } \\
\text { Know }\end{array}$ & Score \\
\hline 1 & $\begin{array}{l}\text { Are there previous conclusive reports on this } \\
\text { reaction? }\end{array}$ & +1 & 0 & 0 & 1 \\
\hline 2 & $\begin{array}{l}\text { Did the adverse event appear after the } \\
\text { suspected drug was administered? }\end{array}$ & +2 & -1 & 0 & 2 \\
\hline 3 & $\begin{array}{l}\text { Did the adverse reaction improve when the } \\
\text { drug was discontinued or a specific antagonist } \\
\text { was administered? }\end{array}$ & +1 & 0 & 0 & 1 \\
\hline 4 & $\begin{array}{l}\text { Did the adverse reaction reappear when the } \\
\text { drug was re-administered? }\end{array}$ & +2 & -1 & 0 & 2 \\
\hline 5 & $\begin{array}{l}\text { Are there alternative causes (other than the } \\
\text { drug) that could solely have caused the } \\
\text { reaction? }\end{array}$ & -1 & +2 & 0 & -1 \\
\hline 6 & $\begin{array}{l}\text { Did the reaction reappear when a placebo was } \\
\text { given? }\end{array}$ & -1 & 0 & 0 & 0 \\
\hline 7 & $\begin{array}{l}\text { Was the drug detected in the blood (or other } \\
\text { fluids) in a concentration known to be toxic? }\end{array}$ & +1 & 0 & 0 & 0 \\
\hline
\end{tabular}




\begin{tabular}{|c|c|c|c|c|c|}
\hline No. & Question & Yes & No & $\begin{array}{l}\text { Don't } \\
\text { Know }\end{array}$ & Score \\
\hline 8 & $\begin{array}{l}\text { Was the reaction more severe when the dose } \\
\text { was increased, or less severe when the dose } \\
\text { was decreased? }\end{array}$ & +1 & 0 & 0 & 1 \\
\hline 9 & $\begin{array}{l}\text { Did the patient have a similar reaction to the } \\
\text { same or similar drugs in any previous } \\
\text { exposure? }\end{array}$ & +1 & 0 & 0 & 0 \\
\hline \multirow[t]{2}{*}{10} & $\begin{array}{l}\text { Was the adverse event confirmed by objective } \\
\text { evidence? }\end{array}$ & +1 & 0 & 0 & 0 \\
\hline & Total Score & & & & 6 \\
\hline
\end{tabular}

Table 2. Interpretation of scores

\begin{tabular}{cl}
\hline Score & \multicolumn{1}{c}{ Result } \\
\hline Total Score $>9$ & $\begin{array}{l}\text { Definite. The reaction (1) followed a reasonable temporal sequence } \\
\text { after a drug or in which a toxic drug level had been established in body } \\
\text { fluids or tissues, (2) followed a recognized response to the suspected } \\
\text { drug, and (3) was confirmed by improvement on withdrawing the drug } \\
\text { and reappeared on reexposure }\end{array}$ \\
& $\begin{array}{l}\text { Probable. The reaction (1) followed a reasonable temporal sequence } \\
\text { after a drug, (2) followed a recognized response to the suspected drug, }\end{array}$ \\
(3) was confirmed by withdrawal but not by exposure to the drug, and \\
Total Score & $\begin{array}{l}\text { (4) could not be reasonably explained by the known characteristics of } \\
\text { the patient's clinical state. }\end{array}$ \\
Total Score 8 & $\begin{array}{l}\text { Possible. The reaction (1) followed a temporal sequence after a drug, } \\
\text { (2) possibly followed a recognized pattern to the suspected drug, and } \\
\text { (3) could be explained by characteristics of the patient's disease. }\end{array}$ \\
Total Score $\leq 0$ & Doubtful. The reaction was likely related to factors other than a drug.
\end{tabular}

The CTZ area consists of several receptors that are sensitive to the causative agent of emesis and produce information on the vomiting center that has a role in the occurrence of vomiting reflexes. Some receptors on CTZ that are identified to cause nausea and vomiting in patients include opioids mu, kappa, dopamine-type 2 (D2), neurokinin-1 (NK-1), and serotonintype 3 (5-HT3) (MacDougall \& Sharma, 2019). As for the side effects of dizziness, it is thought to be due to an imbalance of neurotransmitters in vestibular neuroepithelium (Lee \& Jones, 2017). However, the mechanism of these side effects has not been widely published.

There are various factors other than ropinirole that possibly cause side effects in this patient (as stated in Naranjo Scale point 5), including other medicines, food, or patient's condition. As stated in the paragraph above, the patient also took other medicines, such as trihexyphenidyl, levodopa-benserazide, irbesartan, and isosorbide dinitrate. Those medicines might contribute to the occurrence of side effects in the patient. 
Meanwhile, based on the literature review, another factor that contributes to the occurrence of these side effects in the elderly patient is a change in the patient's pharmacokinetic profile. Ropinirole is inactivated by metabolism in the liver. The principal metabolic enzyme is the cytochrome P450 (CYP) isoenzyme CYP1A2 (Kaye \& Nicholls, 2000). Ropinirole's metabolites are mainly excreted in the urine. Based on previous findings, oral clearance of ropinirole is reduced by approximately $15 \%$ in elderly patients (65 years or above) compared to younger patients (Jost \& Angersbach, 2005). This fact is also supported by the lipophilic properties of ropinirole. The volumes of distribution of ropinirole increase with age. The main effect of the increased volume of distribution is a prolongation of half-life (Mangoni \& Jackson, 2004). Both of these reasons are likely to cause an increase in the concentration of drug which can trigger an increase in drug action and also the side effects. Unfortunately, in this case, the patient did not perform any laboratory tests, so that the other parameters such as AST (aspartate aminotransferase)/ALT (alanine aminotransferase) or creatinine clearance cannot be determined.

The side effects that can be caused by the use of ropinirole depend on the individual sensitivity of the patient. For example, if a patient experiences nausea and vomiting on highdose ropinirole ( $4 \mathrm{mg}$ ), the dose can be reduced to $2 \mathrm{mg}$. However, if it occurs in a small dose (2 $\mathrm{mg}$ ), it can be recommended to stop the treatment and switch to alternative drugs with different target actions. Currently, there is only one brand name which is available in Indonesia, namely ReQuip $2 \mathrm{mg}$ and $4 \mathrm{mg}$ available in a 24-hour prolonged release. Therefore, in the case of this patient, if the side effects occur in low dose use, it is not justified to divide the tablet into 2 pieces since the drug is formulated for controlled release. Splitting controlled-release tablets can damage the film layer of the tablet resulting in a disruption of the method of controlled release of the drug. Therefore, in this patient, drug withdrawal is the appropriate choice while monitoring the effectiveness and side effects of the drug that may occur.

There are several limitations in this study. Some points in the Naranjo Adverse Drug Probability Scale cannot be performed by the researchers, including the administration of placebo to the patient and analysis of blood levels of ropinirole. Both of these are important to support the results of the analysis of drug side effects. Therefore, further research is required to ensure that the side effects occur due to the use of ropinirole.

\section{Conclusion}

Analysis using the Naranjo Adverse Drug Reaction Probability Scale shows that ropinirole possibly causes dizziness and nausea-vomiting in the elderly patient with Parkinson's Disease. The use of ropinirole in Parkinson's patients needs to get more attention from professionals, especially pharmacists. Monitoring should be carried out not only related to the effectiveness of 
the drug but also to the possibility of side effects. Individual dosage adjustments should be applied according to the sensitivity of each individual, especially in elderly patients who have different physiological profiles. Also, pharmacists are expected to be able to provide more education about the possible side effects of the drug to patients and the steps that must be taken when experiencing these side effects. Therefore, the patient's awareness can be increased to support the effectiveness and safety of the therapy.

\section{Acknowledgment}

We would like to express our gratitude to the National Hospital, Surabaya for supporting us during this project.

\section{References}

Grover, S., \& Ghosh, A. (2010). A case of ropinirole-nnduced psychosis. Prim Care Companion J Clin Psychiatry, 12(6): PCC.10100987.

Jost, W.H., \& Angersbach, D. (2005). Ropinirole, a non-ergoline dopamine agonist, S Drug Reviews, 11(3), 253-272.

Kurin, M., Bielefeldt, K., \& Levinthal, D.J. (2018), Prevalence of nausea and vomiting in adults using ropinirole: a systematic review and meta-analysis, Dig Dis Sci, 63(3), 687-693.

Lee, C., \& Jones, T.A. (2017). Neuropharmacological targets for drug action in vestibular sensory pathways, J Audiol Otol, 21(3), 125-132.

MacDougall, M.R.M., \& Sharma, S. (2019). Chemoreceptor trigger zone. Treasure Island (FL): Stat Pearls Publishing.

Mangoni, A.A., \& Jackson, H.D. (2004). Age-related changes in pharmacokinetics and pharmacodynamics: basic principles and practical applications. Br J Clin Pharmacol, 57(1), 6-14.

Kaye, C.M., \& Nicholls, B. (2000). Clinical pharmacokinetics of ropinirole. Clin Pharmacokinet, 39(4), 243-54.

Pahwa, R., Lyons, K.E., Hauser, R.A. (2004). Ropinirole therapy for Parkinson's disease. Expert Review of Neurotherapeutics, 4(4), 581-588.

Pal, K., Smith, A., Hayes, J., \& Chakraborty, A. (2012). Othello syndrome secondary to ropinirole: a case study. Case reports in psychiatry, 2012, 353021.

Shill, H.A., \& Stacy, M. (2009). Update on ropinirole in the treatment of Parkinson's disease. Neuropsychiatr Dis Treat, 5, 33-36. 